\title{
Planejamento e gestão em saúde: flexibilidade metológica e agir comunicativo
}

\author{
Health planning and management: \\ methodological flexibility and communicative action
}

Francisco Javier Uribe Rivera 1

Elizabeth Artmann 1

\footnotetext{
1 Departamento

de Administração

e Planejamento, Escola

Nacional de Saúde Pública, Fundação Oswaldo Cruz, Rua Leopoldo Bulhões 1480, 7o andar 21041-210 Manguinhos Rio de Janeiro, RJ, Brasil uribe@ensp.fiocruz.br
}

\begin{abstract}
This paper intends to analyse the possibilities and the gaps of situational planning, related to the development of dialogical or communicant organizations aim. It stablishes, futhermore, an initial dialog with the health planning streams in Brazil and it defines some research issues that may offer the necessary complement in order to make planning accomplish its function as a communicative action. Key words Health Management; Health Planning; Public Health
\end{abstract}

Resumo Este artigo pretende ser uma reflexão acerca das possibilidades e das lacunas do planejamento situacional no que tange ao desenvolvimento da imagem-objetivo de organizações dialógicas ou comunicantes. Estabelece, ainda, um início de diálogo com as correntes de planejamento de saúde mapeadas no Brasil e define algumas temáticas de investigação que podem oferecer o necessário complemento para que o planejamento cumpra sua função como agir comunicativo.

Palavras-chave Gestão em Saúde; Planejamento Estratégico-Comunicativo; Saúde Pública 


\section{Introdução}

Convidados a realizar uma análise das perspectivas teórico-metodológicas do planejamento/gestão em saúde no Brasil, nos vemos obrigados a assumir uma perspectiva situacional e a resgatar do conjunto de nossas reflexões e leituras um fio condutor, qual seja: o das possibilidades do planejamento estratégico, segundo a nossa matriz cultural, na constituição de organizações solidárias. O termo comunicante atribuído a essas organizações é retirado de Bartolli(1992) apud Rivera (1996a) e corresponde a organizações abertas, evolutivas, flexíveis, com finalidade explícita e responsabilizante para todos.

No desenvolvimento deste excurso, identificamos os aspectos produtivos da proposta do planejamento estratégico situacional e suas lacunas conceituais e metodológicas, procurando indicar possíveis áreas de complementação que poderiam ser motivo de investigação e de aplicação, no intuito de abrir caminho a uma proposta mais ampla e comunicacional do objeto aludido. Desta maneira, tentamos dar um substrato mais prático à alternativa do planejamento comunicativo resgatada de uma crítica ao modelo puramente estratégico (Artmann, 1993; Rivera, 1995).

No percurso do trabalho, procuramos também fazer um mapeamento de tendências na área de planejamento e gestão nos planos nacional e internacional. Não há a intenção de fazer uma análise aprofundada destas, mas de fazer alguns comentários que podem levar a questionamentos delimitadores de objetos de pesquisa.

Deve ficar claro ao longo do trabalho que situamos o planejamento - como momento de desenho - no interior do processo de gerenciamento/gestão de serviços e sistemas. O planejamento, assim, é entendido como ferramenta organizacional, fazendo parte de um processo mais amplo de desenvolvimento das organizações, que valoriza a condução da ação. As próprias possibilidades do planejamento são interpretadas aqui como mediadas/subordinadas à cultura das organizações.

\section{O planejamento situacional como possibilidade instituinte de uma organização comunicante}

O planejamento fracassa na sua tentativa original de obtenção de uma regulação global, imperativa, da sociedade. Enquanto alternativa à economia de mercado, o planejamento dos países socialistas não deixou de ser o modelo de regulação de um ator único, de um ator tecnocrático, que subordinou as relações intersubjetivas a uma visão de desenvolvimento baseada no determinismo econômico.

Os modelos de planejamento global de que o setor saúde se apropria, como o CENDES/ OPS, padecem do mesmo problema, qual seja, a incapacidade de totalização desde uma perspectiva central de atores e instituições díspares, com racionalidades não semelhantes. Há uma incapacidade do Estado de representar a diversidade mediante atos formuladores que substituem a negociação política.

O planejamento estratégico em saúde (PES) surge, em meados da década de 70 , como a tentativa de reconhecimento da complexidade ao introduzir as idéias da superioridade do político sobre o econômico e da diversidade de atores-sujeitos do mesmo ato de planejar. A questão da viabilidade política passa a ocupar um papel central e a definição de propostas/compromissos de ação a depender de uma articulação que se abre a uma perspectiva policêntrica de análise.

Talvez o grande mérito do planejamento estratégico tenha sido o de trazer à tona a iminência do diálogo. Falar em planejamento comunicativo corresponde a uma interpretação do planejamento estratégico matusiano como a possibilidade de uma problematização coletiva, capaz de articular sujeitos sociais, como a possibilidade de incorporação de um raciocínio sobre a governabilidade de situações de compartilhamento e dispersão do poder que enfatiza a negociação política.

Ainda que o planejamento estratégico não tenha colocado com transparência essa perspectiva - sua abordagem do poder enquanto relação entre acúmulos de recursos que são mobilizados em torno do objetivo da vitória de atores individuais oculta essa visão encontramos aspectos que permitem uma interpretação comunicativa. O reconhecimento do ato de planejar como relação interativa, a adoção da negociação cooperativa como meio estratégico possível, a valorização da explicação do 
outro como parâmetro de crítica da nossa própria explicação e possível complemento e, finalmente, o destaque concedido à cultura no delineamento das regras institucionais, são elementos que abrem caminho para uma interpretação menos presa à uma racionalidade pura de fins.

O planejamento comunicativo é assumido como meio de construção de organizações dialógicas. Um aspecto fundamental deste enfoque é a busca da integração, da possibilidade de um projeto solidário, entendido como desafio gerencial permanente. Nesta perspectiva, a escolha dos métodos de desenho ou de análise se subordina a esse objetivo próprio ao campo da gestão. Vários métodos que criem a possibilidade de fluxos de comunicação ampliada e de negociação de compromissos podem ser estimulados. Não há, portanto, a pretensão de uma exclusividade metodológica. $\mathrm{O}$ próprio método deve passar por um confronto com a diversidade.

Vale ressaltar que a perspectiva comunicativa não se reduz à escolha de métodos, mas envolve o processo gerencial como um todo, a partir de uma racionalidade ampliada, para além da racionalidade de fins, considerando o mundo da vida dos atores envolvidos numa postura dialógica que motive a construção de projetos que possam ser assumidos coletivamente como compromissos.

Ajudar a desenvolver uma dinâmica de direção que potencialize o diálogo gerador de compromissos é, então, o fio condutor de uma nova compreensão do planejamento que não consegue mais se divorciar da gestão. Matus (1994a) entendeu muito bem que a viabilidade do modelo racional de planejamento por ele defendido dependia de determinadas características das regras organizacionais, especialmente das regras de responsabilidade que sobredeterminariam a qualidade da gestão.

O triângulo de ferro do PES (Matus, 1994a) é uma boa figura que pode ajudar a delimitar os contornos de uma organização comunicante ou dialógica. Os três vértices representam os principais subsistemas do sistema de direção estratégica a saber a Agenda do Dirigente, que exige concentração no que é estratégico, a Gerência por Operações e o Sistema de Petição e Prestação de Contas. A tese fundamental que o autor sustenta é que a baixa responsabilidade gera uma tendência no sentido da centralização e da ingovernabilidade. Idealmente, o objetivo defendido é a construção de uma organização onde a prestação de contas por resultados seja uma norma interiorizada culturalmente pelos indivíduos, onde haja desconcentração do poder e delegação permanente (uma sábia distribuição do poder de processamento de problemas) e onde predomine um tipo de gestão criativa por operações ou por objetivos.

Matus acredita que com a introdução de novas práticas gerenciais será possível viabilizar uma alta qualidade da gestão. Estas novas práticas gerenciais se confundem com a proposta de seu sistema de direção estratégica que, além dos subsistemas acima destacados, deve ser apoiado por outros como o planejamento estratégico, sistema de informações, etc. A recomendação explícita é de que essa construção siga o modelo de uma reforma organizativa vertical, no sentido de uma reforma radical e seletiva em todos os sistemas relevantes da organização simultaneamente, dada a mútua dependência de todos os subsistemas, cada um gerando demandas para os outros.

A sobredeterminação que as regras de responsabilidade exerceriam sobre toda a dinâmica de gestão reforça a importância da cultura enquanto conjunto de estruturas mentais que subordinaria todas as práticas de trabalho e as derivadas formas organizativas. A necessidade de impactar esse baluarte definidor das virtualidades gerenciais chama a atenção para a prioridade dos componentes Teoria e Treinamento em quaisquer processos de mudança organizacional. Assim, o primeiro passo de uma estratégia de reforma administrativa estaria representado no modelo matusiano pelo desenvolvimento de um centro de treinamento que procuraria promover novas práticas gerenciais e de trabalho.

Sutilmente, o voluntarismo racionalista de Matus encontra um limite nas possibilidades de lidar com cultura. Embora reconheça a primazia da cultura em relação aos processos de trabalho, o autor não aprofunda sua análise em busca de uma proposta de intervenção mais eficaz. A cultura impõe um elemento de moderação que dificulta o estabelecimento de prazos para a mudança organizacional, que se alimenta da indeterminação do processo de mudança cultural (Rivera, 1996a, 1998a; Artmann, 1997a).

Não questionamos a proposta de treinamento e teoria em si, mas devemos relativizar seu impacto quando vista como medida isolada de atuação sobre estruturas mentais. Para 
atingir esse objetivo, o desenvolvimento de práticas educativas permanentes deveria ser acompanhado de mudanças no sistema de gerência. Basicamente, pensamos na introdução de um sistema de gestão criativa que priorize formas de tomada de decisão e de controle coletivas, consensuadas, capazes de estimular a comunicação. A única possibilidade de mudar cultura a longo prazo reside na capacidade de construção legitimada de novas representações que os atores podem ter em função de sua participação em processos comunicativos, de aprendizagem. De qualquer maneira, a cultura terá que ser considerada como elemento de viabilidade ou de modulação da proposta de mudança organizacional. Neste sentido, nas organizações do tipo profissional, segundo classificação de Mintzberg (1989), como é o caso das organizações de saúde, não se justifica a introdução de um sistema pesado de gestão estratégica, do tipo supra-estrutural, mas um conjunto de práticas que de maneira mais informal partilhem da filosofia da intensificação do espírito da gestão por compromissos. O dado cultural da forte autonomia profissional nessas organizações sugere reforçar o objetivo de ajudar os profissionais a internalizar o raciocínio estratégico como parte de seu processo de decisão cotidiano, como alternativa a pesados processos de formalização de planos realizados em instâncias separadas dos centros operadores, de corte tecno-burocrático.

Relacionado a esta questão, temos destacado a necessidade de valorização da reflexão realizada por autores da área da saúde pública (Dussault, 1992; Lima, 1994) acerca dos requisitos em termos de modelo de gestão colocados pela leitura das características das organizações profissionais de saúde. A complexidade do trabalho nessas organizações, a impossibilidade relativa de uma padronização mecanística e a intensa distribuição do poder nas mesmas, sugerem, junto com outras características, um modelo de gestão negociado, de ajustamento mútuo, comunicativo. Isto reforça nossa perspectiva de organização comunicante.

De Matus (1993) resgatamos principalmente os seguintes elementos:

- a idéia de um sistema de gestão descentralizada por operações

- a análise de problemas e de soluções

- aspectos da análise de viabilidade e do desenho estratégico.

É inerente a um sistema de gestão descentralizada a definição de objetivos a partir de problemas colocados fora e dentro da organização (ou macroorganização). A capacidade de processamento destes, entendidos como necessidades declaradas ou demandas, define a qualidade da oferta institucional. A arte de gerir consiste para Matus (1994ª) em saber distribuir bem os problemas pela organização de modo que todos os níveis estejam sempre lidando de forma criativa com problemas de alto valor relativo. $\mathrm{O}$ modelo organizacional proposto por este autor é o de uma organização reflexiva a todos os níveis, como condição de governabilidade.

O caráter totalizador e rigoroso da explicação situacional facilita a escolha de operações de caráter transversal ou horizontal, que transcendem setores, departamentos e unidades e, nesta medida, o planejamento situacional favorece a integração horizontal, sob a forma de uma estrutura matricial por projetos. A horizontalização pode ser entendida aqui como sinônimo de descentralização e de criatividade, de tratamento multidisciplinar.

Há no PES um apelo claro no sentido da coordenação lateral, como alternativa a um tipo de estrutura tipicamente hierárquica. Este elemento característico de estruturas descentralizadas e participativas tem sido destacado pelo Laboratório de Planejamento do Departamento de Medicina Preventiva e Social (LAPA) da Universidade de Campinas, como parte de um modelo que enfatiza, por outro lado, uma boa dose de autonomia das unidades de produção e a necessidade de colegiados de gestão que democratizem a tomada de decisão. Por referência às organizações profissionais de saúde, defendemos a tese de equipes de gestão com representantes das principais categorias profissionais.

A complexidade do PES tem sido suavizada através de propostas e adaptações do método (Artmann, 1993; Cecílio, 1997) que conservam aspectos substantivos do mesmo como a necessidade de uma boa descrição do problema como base para uma explicação eficaz; a diagramação das relações de causalidade sob a forma de uma rede ou árvore simples de causalidade; a definição de nós críticos com base no protocolo ad-hoc do PES e a descrição dos mesmos tendo em vista ajudar à definição do conteúdo mais preciso das propostas de intervenção (operações), vistas como macro-unidades de ação que incidem sobre os nós críticos; a definição por operação da relação recursos/produtos/resultados; uma análi- 
se de viabilidade simplificada baseada na motivação dos atores em relação às operações e na definição de quem controla predominantemente os recursos envolvidos nas operações; e, finalmente, a necessidade de relacionar genericamente estratégias de viabilização e construir indicadores de acompanhamento do plano.

A adaptação e simplificação do PES tem ajudado a evitar uma centralização obsessiva em questões metodológicas reforçando a idéia de que o método é um simples meio a serviço de sujeitos.

Alguns problemas ou deficiências do PES já foram apontadas por nós em alguns trabalhos:

- a inexistência de uma reflexão mais aprofundada sobre cultura enquanto componente da viabilidade de uma intervenção planejada (Artmann, 1993, 1997a; Rivera, 1995, 1996a); - a necessidade de um desenvolvimento específico da tecnologia de negociação cooperativa (Rivera, 1998b);

- uma determinada visão da liderança que destaca a necessidade de um estado maior constituído pelo desenvolvimento de superestruturas de gestão, em detrimento do aperfeiçoamento de habilidades da liderança centradas na capacidade da mediação das relações interpessoais (Rivera, 1996a, 1998a);

- a questão da validade do método para o delineamento ou precisão de uma visão compartilhada sobre a missão institucional (Artmann et al., 1997);

- uma construção ainda muito simplificada da prospectiva, onde predomina uma relação excessivamente determinista do contexto sobre o plano e onde as relações cruzadas entre as variáveis-chave do cenário não são devidamente registradas ou formalizadas; (Rivera, 1998 c);

- a possibilidade de construção de um projeto coletivo a partir da multiplicidade de racionalidades presentes em organizações de saúde;

- dificuldades inerentes à própria complexidade do método.

Estas áreas definem desafios metodológicos importantes.

A questão da cultura nos leva a M. Thévenet $(1986,1993)$, autor francês que destaca a necessidade de uma análise participativa da cultura que colabore para o discernimento de aspectos fortes da cultura que podem ser funcionais à mudança. A visão da cultura como recurso se coloca pragmaticamente a serviço do objetivo de discernir os aspectos da cultura que deveriam ser reforçados para enfrentar problemas correlatos. A relação problemascultura, como definição desafiadora permanente, apresenta a cultura como condição de viabilidade das formas de enfrentamento dos problemas. $\mathrm{O}$ autor propõe uma grade de análise cultural, com categorias de informação marcantes e formas de estabelecimento de hipóteses culturais. $\mathrm{O}$ caráter participativo e sistemático da pesquisa cultural colabora para a possibilidade de realização de um sentido profundo inerente a essa análise, qual seja o de ajudar a desvendar representações sociais compartilhadas, o qual reforça núcleos de colaboração e agregação institucionais. A cultura, enquanto um conjunto de tradições e pré-interpretações de situações, tem um papel determinante na organização e sua abordagem é bastante interessante para a compreensão do mundo organizacional. Contudo, baseados em Habermas (1987), entendemos que as tradições culturais, ainda que condionem fortemente o funcionamento das organizações e a ação dos atores, podem ser questionadas a partir do exercício de um discurso crítico. Esta questão encontra-se abordada no texto de Artmann (1997a).

O PES distingue a negociação (conflitiva, mista e cooperativa) como um meio estratégico possível. A indicação da necessidade de um tal tipo de estratégia não é suficiente se não for acompanhada de uma reflexão mais aprofundada do conteúdo específico da negociação. A Escola de Negociação de Harvard, de Ficher e Ury (1985), enseja uma bom modelo de negociação cooperativa, do tipo ganhar-ganhar, que se aproxima de um modelo argumentativo. Aspectos marcantes deste enfoque são:

- a necessidade de separar a negociação da substância do problema do relacionamento intersubjetivo, que requer um investimento particular;

- a necessidade de negociar a partir dos interesses, dos pressupostos ou motivações das posições, e não das posições mesmas, procurando discernir atrás de posições aparentemente opostas, interesses comuns que podem ser explorados em termos de faixas de acordo, ou interesses distintos, porém não conflitantes, que podem ser harmonizados;

- a idéia de que a negociação é um processo ideativo, criativo, interdisciplinar, de geração de múltiplas opções de ganho mútuo, o qual 
desvirtua a idéia da negociação como um bolo fixo;

- a tese de que o fundamental é negociar critérios de validade universal ou de maior legitimação capazes de balizar objetivamente a possibilidade de um acordo.

O enfoque de negociação de "Como Chegar ao Sim" (1985) pode e deve ser explorado como complemento necessário ao planejamento estratégico e ao desenvolvimento das habilidades da liderança.

O paradigma da "organização que aprende" de Peter Senge dá uma especial atenção à questão da liderança. Em "O Novo Trabalho do Líder" (Starkey, 1997), o autor se contrapõe à visão da liderança forte, carismática, assumindo a liderança como a principal responsável pelos processos de aprendizagem coletiva. Aprender significa incorporar habilidades novas, nunca completamente realizadas, de interação e de reflexão. Estas habilidades básicas, que supõem um questionamento profundo dos modelos mentais, dos pressupostos e crenças dos participantes organizacionais, podem ajudar a consolidar uma visão compartilhada capaz de tensionar a organização em um sentido renovador e produtivo. Não haveria para Senge algo como conteúdos universais e específicos da administração, mas o desafio de criar uma liderança disseminada, como possibilidade de mediação reflexiva das relações interpessoais e de escuta da subjetividade (expressa por meio do não dito que mediatiza negativamente relações de aprendizagem mal sucedidas). Parte importante da proposta deste autor refere-se à necessidade de desenvolvimento de um raciocínio estrutural no que diz respeito à explicação de problemas, buscando-se causas essenciais de alto poder de alavancagem, o qual o aproxima de Matus. Outra contribuição refere-se à necessidade de um desenvolver da técnica de simulação de cenários como instrumento de aprendizagem. Sobre este este último particular, Senge sustenta que a aprendizagem da experiência é limita$\mathrm{da}$, pois a realidade é complexa, sendo difícil o estabelecimento de relações claras de causaefeito entre as decisões que tomamos hoje e suas consequências futuras, dados seus distanciamentos eventuais no tempo e no espaço. Este elemento de indeterminação obrigaria a tentar aprender do futuro, mediante experiências de simulação que essencialmente ajudariam a costurar uma visão de futuro organizacional. Para o autor o grande mérito da pros- pectiva é possibilitar um diálogo sobre os modelos mentais que embasam as visões de futuro, que cria possibilidades harmonizadoras no que tange à visão organizacional. Trazer "a lembrança do futuro" corresponde à tentativa de reforçar uma construção positiva da visão que opere como um polo forte da modelagem do projeto institucional, que se tensiona criativamente com a experiência dos problemas da organização. Há em Senge, baseado na experiência de seguidores da learning organization, uma nova compreensão do planejamento enquanto processo de aprendizagem. O fundamental não seria a elaboração de grandes planos estratégicos, mas a difusão ou incorporação de um raciocínio estratégico pelo corpo organizacional, a ser aplicado no cotidiano das decisões sobre opções alternativas. Coerente com o pensamento de Mintzberg, a estratégia seria o resultado, não de um processo superior destacado no tempo e no espaço, mas de múltiplas interações entre os agentes organizacionais munidos de habilidades comuns como, por exemplo, de análise de sistemas. Este conceito seria o de estratégia emergente, que desde a nossa perspectiva valoriza o planejamento tático-operacional ou o momento tático-operacional do planejamento.

Uma das perguntas que nos colocamos diz respeito à contribuição do PES para o delineamento da missão, dos produtos organizacionais. Em um trabalho relativamente recente, Matus (1994b)) assume que o primeiro desafio da organização é a correta delimitação de seus produtos e responsáveis. O planejamento a partir de problemas terminais, colocados pela ambiência externa, pelos usuários da organização, poderia ajudar a realizar este delineamento. Vários passos seriam necessários: um levantamento exaustivo dos problemas de saúde de uma área de referência; sua priorização em função de critérios sócio-políticos e técnico-sanitários (epidemiológicos, econômicos, de vulnerabilidade, etc.); uma explicação adaptada procurando selecionar nós críticos nas várias áreas de prestação de serviços possíveis, setorial e extra-setorialmente (promoção, prevenção específica, tratamento, acompanhamento, reabilitação, etc.) e, finalmente, uma distribuição das operações-ações entre as várias unidades de serviços de saúde da área (em função do grau de complexidade acordado para as mesmas) e as unidades extra-setoriais. Algumas particularidades do setor teriam que ser respeitadas: critérios espe- 
cíficos de priorização; classificação das operações/ações em várias formas específicas de cuidado/prestação; um planejamento anterior da complexidade das unidades operacionais. A priorização de determinados problemas não pode deixar de se acompanhar de um tratamento extensivo aos problemas menos prioritários, ainda que num nível de manutenção que implique na não piora da situação de saúde. A necessidade de um atendimento universal em saúde leva a considerar o aspecto de rede e aspectos extrasetoriais dos problemas de saúde.

A maior parte das experiências que temos acompanhado nos mostram uma tendência a trabalhar no âmbito dos problemas mais intermediários que afligem uma organização, em detrimento da seleção de problemas terminais no nível de rede local, embora aqueles impactem também os produtos finais. Neste caso, a seleção de problemas pressuporia uma missão previamente definida, a qual reforça a importância de pré-requisito da mesma. Às vezes, a própria falta de clareza sobre a missão aparece como problema (Artmann et al., 1997b). Acreditamos, porém, que há no Brasil um capital acumulado no âmbito da definição da oferta a partir de problemas terminais dentro da corrente da Vigilância à Saúde, que tem produzido instrumentos próprios de programação situacional. Esta abordagem não se chama de programação situacional impunemente: é bastante extensiva e se apoia em formas de territorialização, em formas de estimativa rápida de problemas que esquadrinham minuciosamente regiões, em mapas de risco epidemiológico e social, e finalmente, na dinâmica de explicação de problemas e de desenho de ações.

Esta é, sem dúvida, uma das áreas de pesquisa avaliativa mais importantes do momento. Pensamos, porém, que a situação é tão ou mais complexa no âmbito do setor hospitalar envolvendo também o subsetor privado. Este âmbito está caracterizado, em alguns espaços, por situações de concorrência ou de descoordenação (desintegração, duplicidade), onde se disputa clientela ou recursos. Aqui nos parece útil o enfoque de gestão estratégica hospitalar de Michel Cremadez: La Dèmarche Stratègique (1997).

O enfoque respectivo supõe inicialmente a segmentação ou agrupamento de atividades homogêneas em nível de cada especialidade. Em seguida é realizada a análise estratégica específica de cada segmento em função de duas dimensões: o valor de cada segmento, corres- pondente à capacidade de atração de clientela e ao interesse do hospital de lhe alocar recursos, e a posição competitiva do mesmo, que é função do grau de controle dos fatores chave de sucesso respectivos. Por meio de um sistema de notação, o valor e a posição concorrencial são calculados. A partir desta análise se constrói o portafólio de cada especialidade, que corresponde à localização de todos os segmentos dentro de uma grade constituída pelas duas variáveis ou dimensões anteriores. Este documento serve de base para a definição da estratégia, consistente de três grandes objetivos: segmento que é necessário expandir; segmento que é necessário manter; segmento que é necessário desativar, recortar, negociar com a rede. Finalmente, desenha-se o plano de ação, que implica em geral em atacar os pontos fracos da análise concorrencial e em mexer com aspectos do valor, quando possível.

Este enfoque tem sido aplicado a algumas situações hospitalares e, embora não tenhamos tido tempo de avaliar com mais profundidade estas experiências, que são ainda recentes, detectamos um relativo sucesso no delineamento da missão. Apesar da linguagem típica do planejamento estratégico corporativo, este instrumento ajuda a negociar formas de integração com a rede. Fundamentada na estratégia de diferenciação ou de aprofundamento das competências distintivas, a análise estratégica de Cremadez permite transformar a concorrência frontal em colaboração. É, finalmente, um espaço de comunicação que fortalece a autonomia dos centros operadores e que ajuda a promover mudanças culturais pela difusão do pensamento estratégico ao nível desses centros.

Um confronto PES/Dèmarche acerca das possibilidades da utilização de ambos no caso da formulação da missão é um tema de investigação que estimulamos. Parece-nos que os dois enfoques podem contribuir muito mais do que a Qualidade Total, que para além de seus apelos no sentido das Jornadas de Missão não exibiria enfoques metodológicos tão estruturados.

A questão da prospectiva tem sido embrionariamente desenvolvida por nós à luz de Godet (Rivera, 1998c), com a intenção de preencher lacunas deixadas pelo PES. Do enfoque de Godet duas técnicas nos chamam a atenção: a análise estrutural, que é uma simulação do poder de influência recíproco (duas a duas) das variáveis inicialmente relacionadas para 
construir o cenário do sistema escolhido, e a matriz dos impactos cruzados centrada nas principais tendências ou hipóteses de comportamento das variáveis. A primeira permite reduzir o número de variáveis, ao selecionar as mais importantes (de maior poder de determinação), e a segunda possibilita analisar em que medida uma hipótese de comportamento de uma variável influencia as hipóteses de comportamento das outras. Podemos dizer que estes dois instrumentos são de grande valia na construção de cenários.

Alicerçada na consulta a especialistas para reduzir a subjetividade, na análise do jogo dos atores e em um software baseado em cálculo de probabilidades de cenários, a abordagem de Godet corresponde ao que se tem de mais avançado no campo da prospectiva mais formalizada.

Não se pode esquecer, porém, que a mesma abordagem formalizada pode ser traduzida em um enfoque mais qualitativo e simples, que resgata as duas técnicas acima mencionadas. A simplificação da técnica, posta a serviço da discussão dos modelos mentais dos participantes da simulação, nos moldes da proposta de Senge, parece pertinente.

\section{Panorama dos enfoques gerenciais no mundo}

Da multiplicidade de enfoques existentes quatro correntes que nos parecem expressivas podem ser comentadas sinteticamente: a Gestão da Qualidade Total (QT), a Reengenharia, o Planejamento Estratégico Corporativo e a Learning Organization.

Sobre a QT tecemos comentários em artigo ad-hoc (Rivera, 1996b). Com um discurso estimulante de centralização no cliente e de reconhecimento das relações de confiança fornecedor - cliente como garantia de qualidade, a QT parece não ter estruturado instrumentos e técnicas que lhe propiciem a superioridade metodológica sobre outras correntes, principalmente sobre a variedade de enfoques estratégicos. Apesar de contar com instrumentos de utilidade para a detecção e explicação de problemas (em ambientes participativos), a QT não desenvolveu enfoques próprios de análise de atores e de prospectiva. Isto, somado a toda uma tradição histórica de preocupação estatística com a redução de variedade e com a padronização produtiva, ten- de a fazer dele uma corrente normativa com matizes humanitárias. Recentemente evolui, a partir de uma leitura menos racionalizadora da obra de Deming, para um discurso que sustenta a alternativa de uma Liderança Comunicativa em contraposição à Administração por Objetivos e para a incorporação de elementos da Administração Estratégica, principalmente o conceito de fatores chave de sucesso. Sem um corpo teórico - metodológico próprio e adaptado aos avanços da época, a QT persiste como um remanescente do passado que se alimenta de todos e pretende ser o grande guarda-chuva de todos.

A Reengenharia, vista equivocamente por adeptos da QT como sua continuação, entra no mercado como uma moda de poucas receitas, algumas extremamente válidas, porém de efeitos secundários imprevisíveis; a compactação de processos é uma delas. A crítica à fragmentação exagerada do trabalho e a defesa da criação de equipes de trabalho são fatores que colaboram para uma maior criatividade e diversificação, para uma maior inovação. Menos padronizadora que a QT, a Reengenharia sucumbe pelo peso do autoritarismo, pela pretensão de provocar rupturas organizacionais, pelos motivos ocultos de enxugamento e de demissão de força de trabalho, secundários à tentativa de integração de tarefas e de simplificação dos múltiplos controles anteriores. No campo do planejamento, uma leitura produtiva da Reengenharia, aliada ao enfoque linguístico das organizações de Flores (1989) pode ser verificada em Matus (1994 b) e traz algumas contribuições importantes.

O Planejamento Corporativo Americano, representado por exemplo por Michael Porter (1980, 1986) da Escola de Negócios de Harvard, mostra um grande dinamismo no âmbito das grandes corporações americanas e japonesas. Apoiada na segmentação estratégica das empresas e em um tipo de análise estratégica das possibilidades mercadológicas desses segmentos, este enfoque tem-se mostrado útil para a definição de estratégias que permitam vantagens comparativas. Esta corrente lança mão de vários portafólios de atividades, um dos quais é o portafólio mercado/posição concorrencial, que tem sido adaptado criativamente por Cremadez para uma aplicação em hospitais e no setor público. Restam dúvidas quanto à aplicação do modelo empresarial, não o adaptado por Cremadez, à lógica do setor social. 
Aspectos da Learning Organization já foram comentadas acima em relação à liderança. Apresentado o paradigma na V Disciplina de Senge (1998), constitui-se de técnicas e instrumentos que visam a despertar habilidades de aprendizagem. A questão seria aprender a aprender, através da incorporação de habilidades de reflexão, de indagação, de argumentação, de colocação autêntica. Estas capacidades dizem respeito a cinco disciplinas: a aprendizagem em equipe; o trabalho com modelos mentais; o domínio de si mesmo; a visão compartilhada; o pensamento sistêmico. Um aspecto crítico desta corrente corresponderia ao uso proposto por Senge da idéia de arquetipos sistêmicos ou de regularidades de comportamento para efeitos de aprendizagem. Com esta tentativa Senge reduz os comportamentos globais possíveis das empresas econômicas a uns poucos modelos cuja capacidade de dar conta da diversidade pode ser questionável.

\section{O planejamento de saúde no Brasil}

Mehry fez uma boa classificação do estado da arte em artigo conhecido (1995).

Do nosso ponto de vista, os quatro modelos referidos podem perfeitamente conviver em um fluxo de muita alimentação. De sua diversidade situacional de pontos de vista é possível apreender aspectos que podem vir a ser complementares, ainda que as divergências apontem, por vezes, para a construção de diferentes tipos de modelos assistenciais.

A corrente da Vigilância à Saúde destacase pela busca de operacionalização prática de conceitos do planejamento situacional dentro do contexto da construção da idéia de distrito sanitário como processo social de mudança das práticas sanitárias, no sentido da eficiência e eficácia sociais, eqüidade e democratização. Este processo manifesta-se no espaço local, onde se estabelecem as relações entre instituições de saúde, de preferência ancoradas no paradigma da promoção da saúde, sob a regulação de uma autoridade sanitária local e a sociedade ou grupos sociais, com a diversidade de problemas que se expressam na singularidade daquele território. Este, além de território-solo, constitui-se em território econômico, político, ideológico, cultural e epidemiológico.

Este enfoque enfeixa um conjunto de técnicas de vários campos, do planejamento urba- no-espacial, da epidemiologia, do planejamento estratégico em saúde e da gestão. Nutre um conceito alternativo à velha saúde pública que se destaca pela tentativa de criar horizontalidades entre os velhos programas sanitários, através do planejamento a partir de problemas, baseado na concepção matusiana, em contraposição ao enfoque por programas.

Facilitador de uma visão mais sócio-ambiental do binômio saúde-doença, este enfoque abriria caminho para uma perspectiva de intersetorialidade e de promoção em saúde, contribuindo assim para uma recriação dos modelos assistenciais, a partir de novas práticas sanitárias. Estas práticas sanitárias se constituem em conjuntos de processos de trabalho, articulados em operações, que impõem uma estratégia de ação sobre os nós críticos dos problemas e seus efeitos em um dado território.

Duas práticas sanitárias contraditórias coexistem no Distrito Sanitário. A primeira refere-se à Vigilância à Saúde, direcionada para problemas de enfrentamento contínuo, escolhidos pelo alto impacto nas condições de vida dos grupos populacionais das microáreas. A segunda, a Atenção à Demanda, volta-se para a intervenção pontual, ocasional sobre os efeitos dos problemas ao nível individual, autopercebidos e é considerada estratégica para a legitimidade social do projeto e para a captação de informações para a Vigilância à Saúde que, pretende-se, venha a ser a prática hegemônica.

Um problema deste enfoque poderia estar representado pela ausência de uma proposta que dê conta das particularidades do âmbito hospitalar.

A corrente da Programação em Saúde da USP propõe a construção de um sistema de saúde programado em termos de suas atividades a partir da Epidemiologia Social. Visa a reduzir uma lógica de atenção espontaneista, de mercado. Afirma-se em um tipo de construção micro política de novas práticas assistenciais, de referenciamento a equipes de saúde integral (em vários campos do atendimento). Busca promover novas aglutinações dos programas tradicionais em conjuntos mais amplos e modernos, privilegiando o componente populacional. Os autores identificam uma evolução da programação de uma posição de "técnica de planejamento" (racionalização econômica do processo de produção em saúde) para um significado de "modelo assistencial 
ou modelo operatório das práticas de saúde" (tecnologia de trabalho), integrando a prática médica e a sanitária, apresentando-a como um campo de experimentação de novas formas de trabalho em saúde. Problemático pode ser para esta corrente o grau de subordinação da velha clínica a uma racionalidade programada. Talvez seja menos voluntarioso pensar em termos de uma tensão permanente entre demanda programada e espontânea, no contexto da qual procurar-se-ia uma hegemonia relativa da primeira (nos termos da Vigilância à Saúde). Destaca-se ainda a externalidade das questões de viabilidade com relação ao método.

Em relação à corrente da Gestão Estratégica e do Planejamento de Saúde articulada ao Modelo Tecno-assistencial em Defesa da Vida, do LAPA, já comentamos os esforços desenvolvidos na direção do desenvolvimento de uma tecnologia leve de planejamento (a partir do enfoque matusiano e do ZOPP). Sua noção de caixa de ferramentas (composição de técnicas, procedimentos e enfoques adaptados do PES, de Mário Testa, de elementos teóricos da psicanálise e da análise institucional, entre outros) dá uma idéia da flexibilidade de abordagem e da diversidade de instrumentos manipulados por esta corrente que experimentou em profundidade tanto o planejamento situacional quanto o enfoque de qualidade total. Sua riqueza se explica pela acumulação de experiências (de condução e de consultoria/pesquisa) tanto na rede básica quanto no campo hospitalar, ainda que parta inicialmente de uma concepção redebasicocêntrica propondo depois, uma inversão na clássica pirâmide para um círculo, onde o sistema admitiria várias portas de entrada, segundo a melhor tecnologia e oportunidade para cada usuário. Uma flexibilização dos critérios de hierarquização sempre foi defendida pela proposta do LAPA. O território é visto com restrições: é importante definir a área de responsabilidade das instituições de saúde, mas o usuário não pode ser aprisionado numa área restrita, pois se movimenta no sistema em busca da satisfação de suas necessidades. A concepção tradicional e verticalizada de programas é substituída pela formulação criativa de equipes locais, organizadas buscando evitar corporativismos e monitoradas por avaliações de desempenho referenciadas por metas vinculadas aos objetivos definidos para os serviços. A proposta de organização do sistema de saúde visa a dar conta das relações entre os diversos tipos de produtores, tendo nos gerentes locais/regionais uma base fundamental de articulação, onde todos os produtores deveriam estar submetidos ao controle público. A relação da unidade de saúde com a população é estruturada com algumas noções emprestadas da área de Saúde Mental: vínculo e responsabilidade e acolhimento, procurando-se desenvolver uma relação personalizada e humanizada.

Sua crítica às propostas tecnocráticas e prescritivas em planejamento e gestão que pressupõem uma precedência dos métodos em relação aos sujeitos é por nós partilhada. Segundo Matus, o método serve, no máximo para ajudar a sistematizar o conhecimento da realidade e não substituí-lo. Quem planeja é sempre o ator. Para Matus, um ator com conhecimento do problema e capacidade de raciocínio estratégico com certeza enfrentará melhor um problema do que alguém com baixo conhecimento da realidade e apenas conhecimento de método, por melhor que este seja. De todo modo, não há como negar a importância de métodos que ajudem a dar conta da complexidade da tarefa de gerir situações que apresentam variáveis não controláveis e que exigem respostas eficazes, criativas e flexíveis.

Partilhamos ainda da preocupação com o sujeito, e especificamente com a subjetividade, o que parece ser um diferencial analítico na proposta do LAPA. Embora não se tenha um quadro claro ainda de como a análise institucional recuperaria a subjetividade dos agentes em processos de autonomização e de instituição de novas relações de poder capazes de democratizar amplamente estruturas organizacionais, cumpre registrar, no entanto, o esforço desenvolvido nesta direção.

A abordagem comunicativa em planejamento, que tem origens a partir de reflexões teóricas sobre experiências com o enfoque do PES e do estabelecimento de um diálogo com a Teoria da Ação Comunicativa de Habermas, apresenta hoje vários desdobramentos teórico-metodológicos e pragmáticos, alguns expostos na primeira parte deste texto. Alguns destes desdobramentos merecem ser aprofundados através de linhas de investigação, das quais ressaltamos as seguintes:

- análise da cultura enquanto componente de viabilidade de um projeto, objetivando uma metodologia de escuta da cultura, o estabelecimento da relação cultura-problemas em face de uma determinado macroproblema e o de- 
senho de estratégias de utilização da cultura como recurso da intervenção sobre problemas; - desenho metodológico e missão institucional, envolvendo uma análise comparativa das possibilidades do PES e do enfoque de Cremadez, em vários níveis de atenção em saúde; - desenvolvimento de habilidades de liderança e de negociação, que configuram junto com o trabalho cultural o campo do que denominamos gestão pela escuta;

- discussão teórica geral sobre a relação entre a gestão pela escuta e os métodos racionalistas de gestão;

- aplicação mais sistemática da prospectiva enquanto recurso crucial dentro do cálculo estratégico;

\section{Referências}

Artmann E 1993. O Planejamento Estratégico Situacional: a Trilogia Matusiana e uma Proposta para o Nível Local de Saúde (uma Abordagem Comunicativa). Dissertação de mestrado, Escola Nacional de Saúde Pública, Fiocruz, Rio de Janeiro.

Artmann E 1997a. Cultura e Mudança Organizacional. Universidade de Campinas, Campinas, mimeo.

Artmann E, Azevedo CS, Sá MC 1997b. Possibilidades de aplicação do enfoque estratégico de planejamento no nível local de saúde: análise comparada de duas experiências. Cadernos de Saúde Pública 13(4): 723-740.

Dussault G 1992. Gestão dos serviços de saúde. características e exigências. RAP, RJ, 26: 8-19.

Cecílio LCO 1997. Uma sistematização e discussão de tecnologia leve de planejamento estratégico aplicada ao setor governamental, p.161-167. In EE Merhy \& R Onocko (orgs.). Agir em Saúde: um Desafio para o Público. Hucitec, SP.

Crémadez M 1997. Le Management Stratégique Hospitalier. InterEditions, Paris.

Fisher R, Ury W 1985. Como Chegar ao Sim: a Negociação de Acordos sem Concessões. Imago, Rio de Janeiro.

Flores F 1989 Inventando la Empresa del Siglo XXI. Hataché, Santiago, Chile.

Habermas J 1987. Teoria da la Acción Comunicativa. Taurus, Madrid.

Lima SML 1994. Definição e implementação de objetivos nas organizações públicas de saúde. RAP, RJ, 28: 38-64.

Matus C 1993. Política, Planejamento e Governo. Ipea, Brasília.

Matus C 1994a. Sobre la Teoria de las Macroorganizaciones. Revista PES, Santafé de Bogotá, 3.

Matus C 1994b. El Metodo PES, Reingenieria Publica y la Teoria de las Conversaciones: Trabas y Problemas. Revista PES, Santafé de Bogotá, 2.

Merhy EE 1995. Planejamento como tecnologia de gestão: tendências e debates em planejamento em saúde no
- possibilidades de diálogo entre o planejamento situacional e os enfoques da administração estratégica e do planejamento estratégico corporativo, favorecendo uma abordagem do contexto de mix público/privado;

- o resgate da subjetividade no campo da gestão, em processos de construção coletiva de projetos institucionais, a partir do conceito amplo de razão.

É importante considerar a interrelação destas várias linhas e a preocupação com o desenvolvimento de métodos/enfoques, posturas e condutas que aprofundem processos de solidariedade e geração de compromissos compartilhados num permanente aprender a aprender.

Brasil, p.117-194. In E Gallo (org.) Razão e Planejamento. Reflexões sobre Política, Estratégia e Liberdade. Hucitec/Abrasco, São Paulo, Rio de Janeiro.

Mintzberg H 1989. Mintzberg on Management: Inside our Strange World of Organizations. The Free Press, New York.

Porter M 1980. Choix Stratégiques et Concurrence. Economica, Paris.

Porter M 1986. L'Avantage Concurrentiel. Comment Devancer ses Concurrents e Maintenir son Avance. InterEditions, Paris.

Rivera FJU 1995. Agir Comunicativo e Planejamento Social (uma Crítica ao Enfoque Estratégico), Fiocruz, Rio de Janeiro.

Rivera FJU 1996a. A gestão situacional (em saúde) e a organização comunicante. Cadernos de Saúde Pública 12(3): 357-372.

Rivera FJU 1996b. Planejamento estratégico-situacional ou controle de qualidade total? Um contraponto teórico-metodológico. Cadernos FUNDAP 19: 25 45.

Rivera FJU 1998a. Cultura, Liderança Comunicativa e Gestão. Escola Nacional de Saúde Pública, Rio de Janeiro. Mimeo.

Rivera FJU 1998b. Comunicação e Negociação Gerencial (como requisito das organizações profissionais de saúde). Escola Nacional de Saúde Pública, Rio de Janeiro. Mimeo.

Rivera FJU 1998c. Análise Estratégica e Prospectiva, Escola Nacional de Saúde Pública, Rio de Janeiro. Mimeo.

Senge P 1998. A Quinta Disciplina. Arte e Prática da Organização que Aprende. BestSeller, São Paulo.

Starkey K 1997. Como as Organizações Aprendem. Futura, SP.

Thévenet M 1993. La Culture d'Entreprise. Presses Universitaires de France, Paris.

Thévenet M 1986. Audit de la Culture d'Entreprise. Les Editions d'Organisation, Paris. 